\title{
Quality of life of patients with central serous chorioretinopathy - a major cause of vision threat among middle-aged individuals
}

Izabella Karska-Bastaㄹ ${ }^{1}$ Weronika Pociej-Marciak ${ }^{1}$, Michał Chrząszcz ${ }^{2}$, Katarzyna Żuber-Łaskawiec ${ }^{1}$, Marek Sanak³ ${ }^{3}$ Bożena Romanowska-Dixon ${ }^{1}$

\begin{abstract}
${ }^{1}$ Clinic of Ophthalmology and Ocular Oncology, Department of Ophthalmology, Jagiellonian University, Krakow, Poland

${ }^{2}$ Clinic of Ophthalmology and Ocular Oncology, University Hospital, Krakow, Poland ${ }^{3}$ Division of Molecular Biology and Clinical Genetics, Department of Internal Medicine, Jagiellonian University, Krakow, Poland
\end{abstract}

Submitted: 11 September 2019; Accepted: 27 December 2019;

Online publication: 29 January 2020

Arch Med Sci 2021; 17 (3): 724-730

DOI: https://doi.org/10.5114/aoms.2020.92694

Copyright $\odot 2020$ Termedia \& Banach

\begin{abstract}
Introduction: The 25-item National Eye Institute Visual Function Questionnaire (NEI VFQ-25) was designed to measure the vision-related quality of life (QoL). We aimed to assess the effect of disease duration, disease type (i.e., acute vs. chronic and unilateral vs. bilateral), and selected sociodemographic data on the QoL of patients with central serous chorioretinopathy (CSC).

Material and methods: The study included 79 patients diagnosed with CSC. The QoL was assessed using the NEI VFQ-25. The statistical analysis was performed using IBM SPSS Statistics 24.

Results: A significant positive correlation was found between deterioration in peripheral vision as assessed by the NEI VFQ- 25 and duration of CSC $(r=-0.22, p=0.046)$. Compared with women, men obtained higher scores on the scales assessing general health, mental health, ocular pain and role limitations ( $p=0.018, p=0.027, p=0.009$ and $p=0.007$, respectively). Patients with acute CSC reported higher levels of social functioning as compared with those with chronic CSC $(p=0.04)$. There were no differences in any of the scales between patients with unilateral and bilateral CSC. Elderly patients obtained lower scores on 9 of the 12 analyzed scales, as compared with younger patients $(p<0.05)$.

Conclusions: Patients with CSC do not assess their QoL in negative terms, which may be related to the fact that the disease presents with transient symptoms. However, the QoL deteriorated with longer disease duration. Men with CSC have better vision-related QoL than women.
\end{abstract}

Key words: health-related quality of life, vision disorders, retina, questionnaire.

\section{Introduction}

Central serous chorioretinopathy (CSC) ranks among the most common sight-threatening retinopathies, together with age-related macular degeneration (AMD), diabetic retinopathy and branch retinal vein occlusion [1, 2]. The incidence of the disease, as estimated by Kitzmann et al. [3], is 9.9 (95\% confidence interval $(\mathrm{Cl}): 7.4-12.4)$ per 100,000 in men and $1.7(95 \% \mathrm{Cl}: 0.7-2.7)$ in women. The limited literature data suggest

\author{
Corresponding author: \\ Izabella Karska-Basta PhD \\ Clinic of Ophthalmology \\ and Ocular Oncology \\ Department \\ of Ophthalmology \\ Jagiellonian University \\ Krakow, Poland \\ Phone: +48501533915 \\ E-mail: izabasta@gmail.com
}


comparable rates of CSC across white, Asian, and African American populations [4-6]. A study on the prevalence of retinal diseases in older adults in Poland reported that chronic CSC constitutes less than $1 \%$ of all diagnoses [7]. The condition is caused by a central retinal detachment, secondary to damage of retinal pigment epithelium (Figure 1), and it is characterized by metamorphopsia and painless loss of central vision [8]. Most published reports differentiate between an acute and a chronic form of CSC using a threshold of 6 months since diagnosis [9].

Central serous chorioretinopathy was first described in detail by von Graefe in 1986 [10]. Nevertheless, its pathogenesis remains unclear [11-13]. The age of affected patients varies in the literature, with a recent epidemiological study reporting a mean age ranging between 39 and 51 years [14]. Also, more common occurrence of CSC has been associated with male sex, steroid therapy, general hypertension, alcohol abuse, Cushing disease, Helicobacter pylori infection, pregnancy, cigarette smoking, and stress $[12,15,16]$. Central serous chorioretinopathy is a self-limited disorder with a favorable visual prognosis in most cases; nonetheless, $31 \%$ of CSC patients experience disease recurrence within a median time of 1.3 years (range: $0.4-18.2$ ) [17]. In $10 \%$ to $20 \%$ of cases, progressive visual loss may develop $[18,19]$.

Recent reports have indicated that the assessment of the quality of life $(\mathrm{QoL})$ is an essential tool for estimating the burden of various diseases [20-22]. Quality of life is defined by the World Health Organization as "an individual's perception of their position in life in the context of the culture and value systems in which they live and in relation to their goals, expectations, standards and concerns" $[23,24]$. So far, only a few studies have been published on the QoL of patients with CSC [15, 25-27]. Patients with CSC were generally reported to have worse vision-related QoL than people without this disease $[25,26]$.

The goal of CSC treatment is similar to that of other types of treatment for sight-threatening eye diseases. For example, according to the European
Glaucoma Society, glaucoma treatment is aimed at maintaining the patient's visual function and related quality of life, at a sustainable cost [28, 29].

To date, assessment of vision-related QoL, based on the National Eye Institute Vision Function Questionnaire (NEI VFQ-25), of only 30 patients with chronic CSC has been reported [25]. Thus, the main purpose of our study was to analyze QoL of a large group of patients with CSC, depending on the duration of the disease, its form (i.e., unilateral vs. bilateral, and acute vs. chronic) and selected socio-demographic data (i.e., age, sex, marital status, and place of residence).

\section{Material and methods}

The study included 79 adult white patients (60 men and 19 women) diagnosed with CSC at the Department of Ophthalmology, Jagiellonian University in Krakow, Poland, between January and December 2017.

The diagnosis of CSC was based on typical findings in the fundus of the eye documented by digital photography, fluorescein angiography, and optical coherence tomography. Patients were classified into 2 groups: with acute CSC (disease duration < 6 months) and with chronic CSC (disease duration $\geq 6$ months).

The QoL was evaluated with the NEI VFQ-25, version 2000, which has been validated in Poland [30]. RAND Corporation granted permission to use the NEI VFQ-25 without any charge to all researchers on condition that they identify the measure as such in all their publications [31]. Specific information is provided on the cover page of the NEI VFQ-25 itself. The responses of patients were scored in accordance with the NEI VFQ-25 calculation algorithm [31]. The NEI VFQ-25 consists of 25 questions assessing the patient's general health, general vision, ocular pain, near vision, distance vision, peripheral vision, color vision, driving, as well as vision-specific social functioning, mental health, role difficulties, and dependency [30, 31]. The content of the questions was based on the results from a series of focus groups including pa-
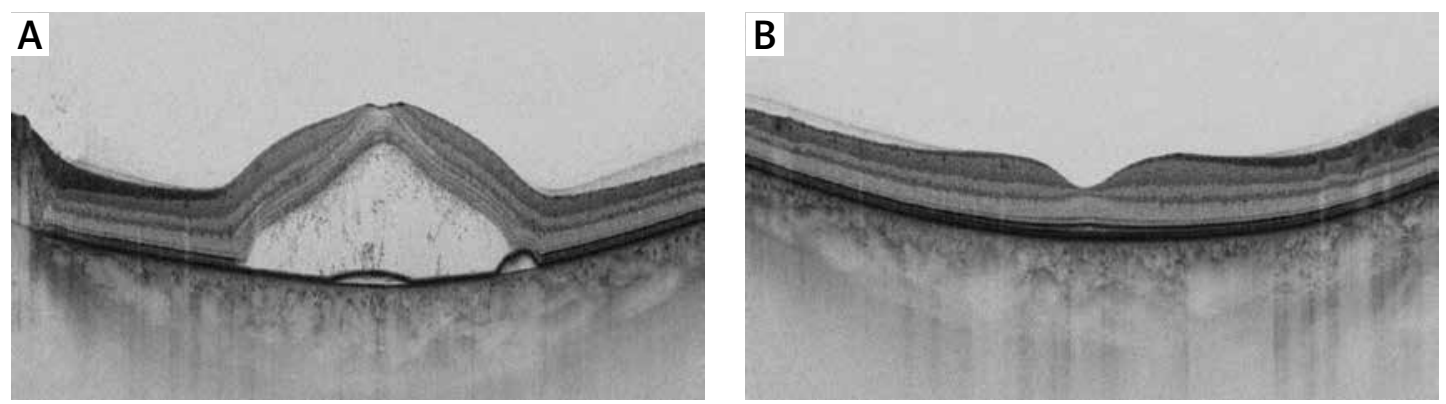

Figure 1. Swept source optical coherence tomography image of the macula showing the subretinal fluid under the neurosensory retina concomitant with pigmented epithelium detachment (A), proper macular morphology of the contralateral eye (B) 
tients with specific eye conditions such as AMD, glaucoma, age-related cataracts, cytomegalovirus retinitis, or diabetic retinopathy [31]. The response scales were scored as follows: for questions 1 to 16 - from the most positive to the most negative; and for questions 17 to 25 - from the most negative to the most positive [32]. In our procedures, we followed the NEI VFQ manual of operations [31]. The questionnaire subscale scores were an average of the questions in the subscale changed to a 0 to 100 scale, where 100 denoted the best possible score on the measure (best visual functioning) and 0 represented the worst possible score (worst visual functioning) [31, 32]. The final NEI VFQ-25 score was an unweighted average of the responses to all questions except the one pertaining to the general health evaluation (question number 1) [31]. Of note, the general health item is reported as a separate score to reflect an overall health condition in population-based studies and enable a comparison for NEI VFQ-25 respondents [31].

The study was approved by the Bioethics Committee of Jagiellonian University (No. 122.6120.266.2016). All patients provided written informed consent to participate in the study.

\section{Statistical analysis}

Qualitative data were presented as counts and percentages. Quantitative data were given as means and standard deviations (SD) for normally distributed variables and medians and quartiles for those with non-normal distribution. The nor-

Table I. Results of quality of life scales from the 25item National Eye Institute Visual Function Questionnaire (NEI VFQ-25) for the study group. Data are shown as median and interquartile range (Me $(I Q R))$ for non-normally distributed variables

\begin{tabular}{|lc|}
\hline Quality of life scale & Patients with CSC \\
\hline General health & $50.00(25.00-75.00)$ \\
\hline General vision & $60.00(60.00-80.00)$ \\
\hline Ocular pain & $75.00(62.50-87.50)$ \\
\hline Near activities & $75.00(58.33-83.33)$ \\
\hline Distance activities & $83.33(75.00-100.00)$ \\
\hline Social functioning & $100.00(87.50-100.00)$ \\
\hline Mental health & $75.00(62.50-87.50)$ \\
\hline Role difficulties & $75.00(50.00-87.50)$ \\
\hline Dependency & $100.00(91.67-100.00)$ \\
\hline Driving ability & $83.33(60.42-91.67)$ \\
\hline Color vision & $100.00(100.00-100.00)$ \\
\hline Peripheral vision & $100.00(75.00-100.00)$ \\
\hline CSC - central serous chorioretinopathy.
\end{tabular}

mality of quantitative variables was tested using the Kolmogorov-Smirnov test and inspection of box plots and Q-Q plots. Quantitative variables were compared between the two groups using the Mann-Whitney test. The strength of the relationship between two interval variables was estimated using the Pearson correlation coefficient $(r)$ for linearly related variables and the Spearman correlation coefficient (rho) for nonlinearly related ones. Relationships between two quantitative variables were presented using scatterplots, and the shape of the relationship was drawn using the loess curve. A p-value of less than 0.05 was considered significant. The statistical analysis of the collected material was performed using the IBM SPSS Statistics 24 software for Windows.

\section{Results}

The study included 60 (76\%) men and 19 (24\%) women. The mean age of patients was $46.7 \pm 9.0$ years. The mean duration of symptoms was 44.9 \pm 45.6 months. Acute CSC was diagnosed in 24 (30\%) patients, and chronic CSC in 55 (70\%). In $61(77 \%)$ patients, the disease affected one eye, and in 18 (23\%) patients, both eyes. There were $28(35 \%)$ patients living outside of the city and $51(65 \%)$ patients living in the city. Sixteen (20\%) patients were single, while $63(80 \%)$ were in a stable relationship.

The highest scores were noted for the following scales of the questionnaire: color vision, dependence, social functioning, and peripheral vision. The lowest values were recorded for general health and general vision. Detailed data for the individual QoL scales in the study group are shown in Table I.

There were no correlations between any of the QoL scales and unilateral or bilateral CSC $(p>0.05)$. Patients with acute CSC scored higher only on the social functioning scale as compared with patients with chronic CSC $(p=0.04)$.

We did not observe any significant relationships between disease duration and QoL, except for the peripheral vision scale $(p<0.05)$. The score for peripheral vision assessment decreased with disease duration $(r=-0.22, p=0.046$; Figure 2$)$.

A significant relationship was observed between sex and general health, ocular pain, mental health, and role difficulties. Men scored higher than women on all these scales. Detailed data are shown in Table II.

Interestingly, our analysis revealed a strong negative correlation between age and the scores on 9 of the 12 questionnaire scales $(p<0.05)$ : the patients' assessment of their general health (rho $=-0.45, p<0.001$ ), near vision (rho $=-0.44$, $p<0.001$ ), distance vision ( $r h o=-0.41, p<0.001$ ), as well as vision-specific mental health (rho $=-0.32$, 
$p=0.004$ ), role difficulties (rho $=-0.32, p=0.005$ ), dependency (rho $=-0.25, p=0.024$ ), color vision (rho $=-0.27, p=0.016$ ), peripheral vision ( $r h o=-0.22$, $p=0.048$ ), and social functioning (rho $=-0.32, p=$ 0.005) (Figure 3).

We did not observe any relationship between the scores on any of the questionnaire scales and the place of residence or marital status $(p>0.05)$.

\section{Discussion}

Studies published to date indicate that the QoL of patients with CSC is lower than that of the non-CSC population [25, 26]. Lajmi et al. [27] reported that CSC affects the psychological state and QoL of generally young and professionally active individuals. This can impair their work performance and cause temporary or permanent disability [27].

Sahin et al. [26] analyzed psychological symptoms and QoL in a group of 30 patients with acute CSC. The authors used the Symptom Check List90 Revised for psychological evaluation and Short Form 36 for QoL assessment [26]. In turn, Türkcü et al. [25] investigated 30 patients with chronic CSC, using the NEI VFQ-25. Both Sahin et al. [26] and Türkcü et al. [25] found that CSC reduces the QoL of affected patients.

It was reported that most cases of acute CSC resolve spontaneously [17]. Some patients, however, experience recurrent or chronically persistent macular subretinal fluid. In our study, we explored a potential relationship between the respective questionnaire scales and disease duration. In our analysis, duration of CSC was not associated with any of the QoL scales except for peripheral vision.

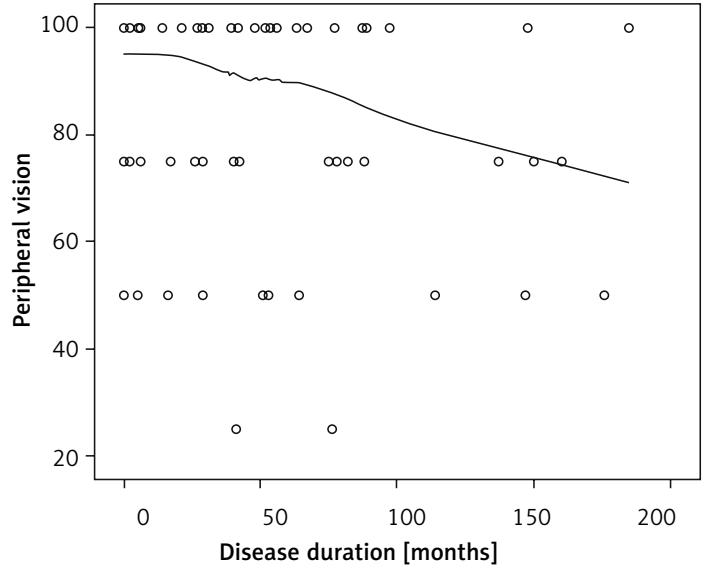

Figure 2. Scatterplot showing the relationship between peripheral vision and duration of central serous chorioretinopathy (Pearson's $r=-0.22$, $p=0.046)$

Interestingly, this may be explained by the fact that the scores of individual scales did not vary considerably and tended to concentrate in the upper ranges. However, our analysis indicates that the condition of patients with both acute and chronic CSC is favorable. In a prospective study with a 12-month follow-up, Breukink et al. [15] assessed the QoL of 36 patients with CSC. They used the NEI VFQ-39, which is an extended version of the NEI VFQ-25 used in our analysis. Contrary to our observations, they found that the QoL of patients significantly deteriorated in almost all categories along with disease duration, as compared with controls [15]. This discrepancy may be related to the cross-sectional design of our study.

In a study by Türkcü et al. [25], patients with chronic CSC obtained worse scores on the NEI

Table II. Correlation between quality of life and sex of CSC patients. Data are shown as median and $1^{\text {st }}$ and $3^{\text {rd }}$ quartiles (Me (Q1-Q3)) for non-normally distributed variables

\begin{tabular}{|lccc|}
\hline Variable & Men with CSC & Women with CSC & $P$-value \\
\hline General health & $50(50-75)$ & $50(25-50)$ & 0.018 \\
\hline General vision & $60(60-80)$ & $60(40-80)$ & 0.160 \\
\hline Ocular pain & $75(63-94)$ & $63(50-75)$ & 0.027 \\
\hline Near activities & $75(58-88)$ & $83(67-92)$ & 0.373 \\
\hline Distance activities & $92(75-100)$ & $100(88-100)$ & 0.777 \\
\hline Social functioning & $100(88-100)$ & $69(56-69)$ & 0.009 \\
\hline Mental health & $78(69-88)$ & $50(25-75)$ & 0.007 \\
\hline Role difficulties & $75(56-88)$ & $100(92-100)$ & 0.616 \\
\hline Dependency & $100(88-100)$ & $67(58-83)$ & 0.216 \\
\hline Driving ability & $83(67-92)$ & $100(100-100)$ & 0.749 \\
\hline Color vision & $100(100-100)$ & $100(75-100)$ & 0.835 \\
\hline Peripheral vision & $100(75-100)$ & 675 \\
\hline
\end{tabular}

CSC - central serous chorioretinopathy. 

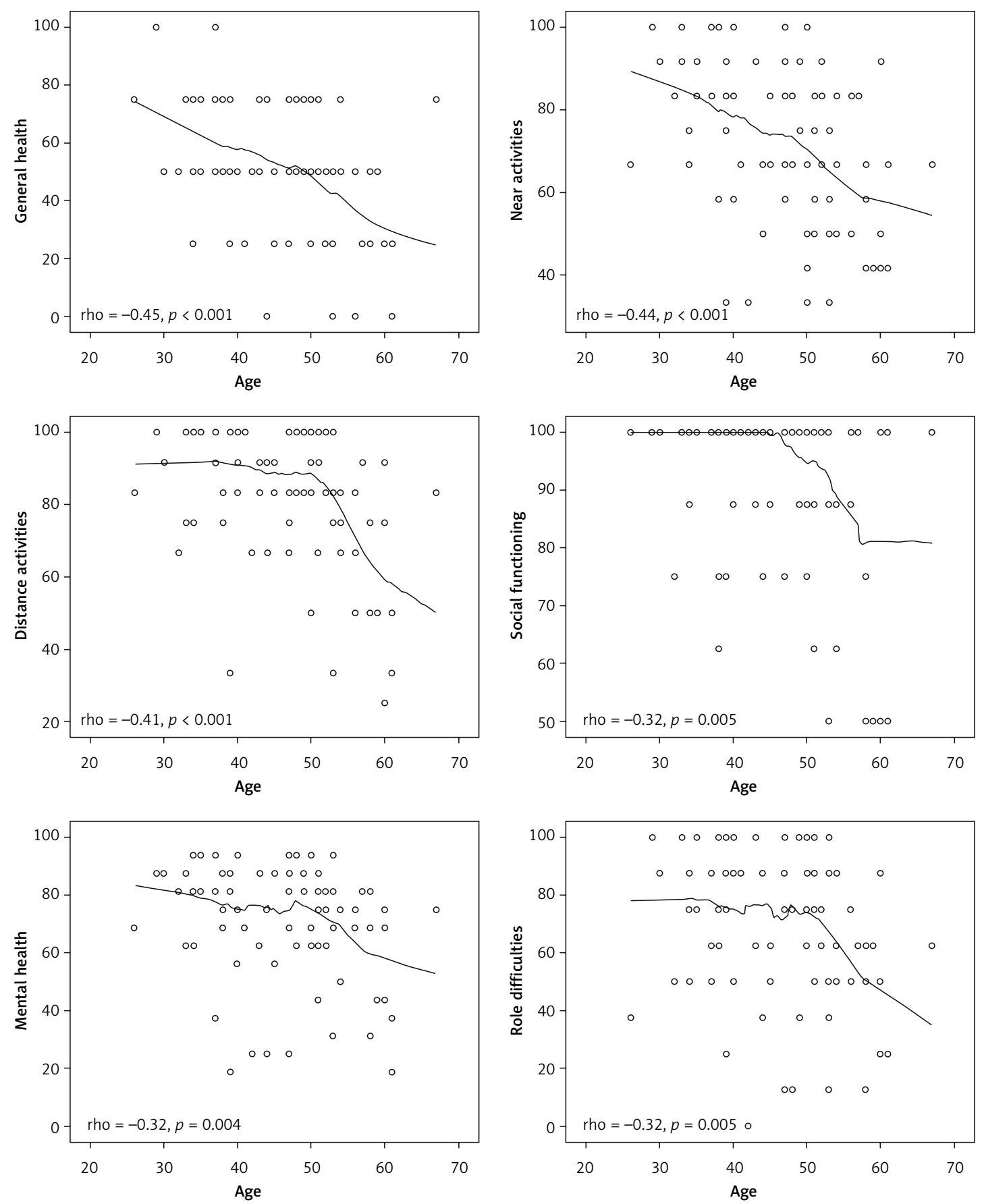

Figure 3. Scatterplots showing the relationship between age and respective scales of the 25-item National Eye Institute Visual Function Questionnaire (NEI VFQ-25)

VFQ-25 scales except for general health, as compared with controls. Similarly, in our study, the score on the social functioning scale was lower for patients with chronic CSC than for those with acute CSC. This may be explained by the worsening of vision function associated with long disease duration.

Our study did not reveal any relationship between the QoL and either the unilateral or bilateral form of CSC. This may be associated with the lack of serous retinal detachment in the macula and vision deterioration in the affected eye during remission. Moreover, asymptomatic patients may have presented a single or multiple episodes of extramacular serous detachment. This phenomenon is also commonly observed in the contralateral eye of CSC patients [33]. However, further research is needed to confirm this hypothesis. Interestingly, in neovascular AMD, the vision-related QoL was lower in patients with both eyes affected than in those with the involvement of a single eye [34]. This may be due to the 

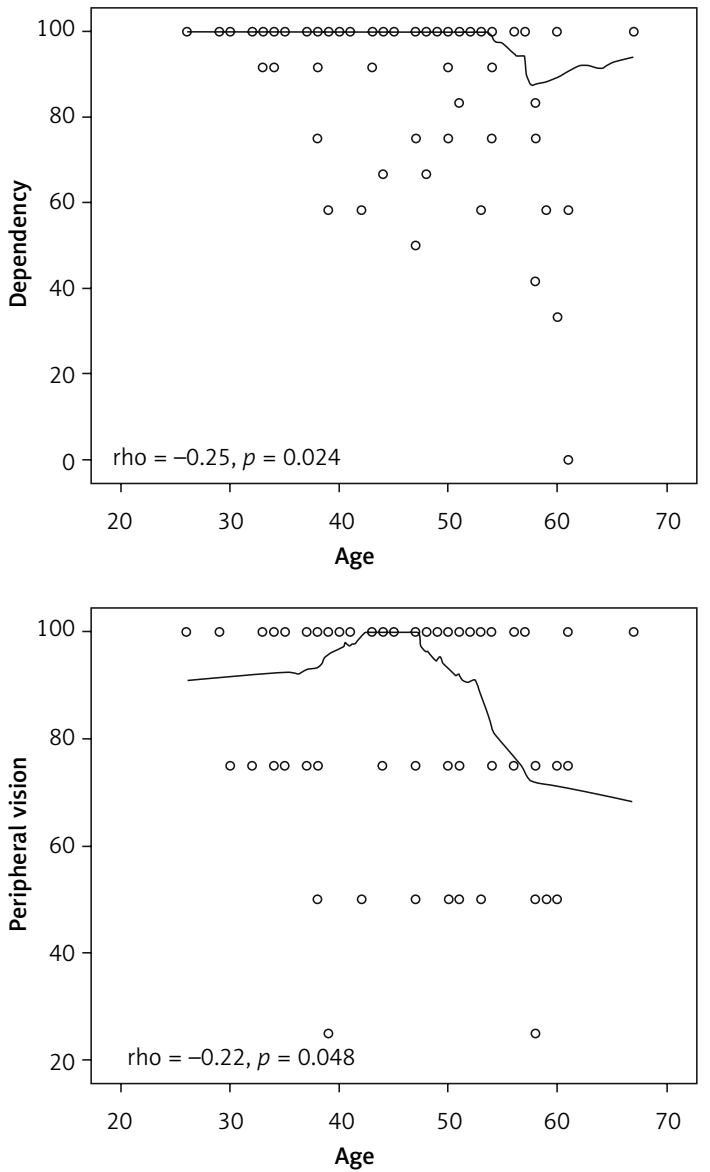

progressive nature of this maculopathy with no periods of remission.

Nickels et al. [29] conducted a large population-based study of mainly Caucasian ethnicity to provide a reference for comparison for future research evaluating the effect of eye diseases on the QoL. In line with the study by Nickels et al. [29], our results support the association of vision-related QoL with age and sex [35]. We observed the strongest association between a worse QoL and older age (lower scores for 9 of the 12 scales in the NEI VFQ-25). Based on the literature, it can be speculated that women report more medical problems and more diseases than men, and they tend to assess their health in more negative terms [36, 37]. In keeping with other studies, we found that female patients rated their general health, mental health, role difficulties, and ocular pain worse than men. Based on our sociodemographic data, we did not detect any relationship between the QoL and marital status and place of residence.

Our study has several limitations, including its cross-sectional design and the fact that it was conducted at a single time point.

In conclusion, we demonstrated that patients with CSC do not assess their QoL in negative terms. This may be related to the fact that the disease presents with transient symptoms. How-

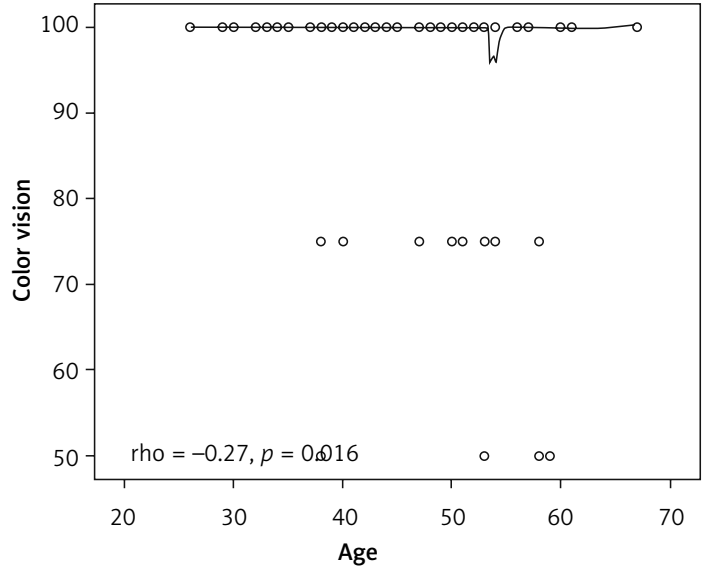

Figure 3. Cont. Scatterplots showing the relationship between age and respective scales of the 25 item National Eye Institute Visual Function Questionnaire (NEI VFQ-25)

ever, the QoL was shown to decrease with long duration of CSC. Our study emphasizes that the possible impact of CSC on the QoL should not be underestimated.

\section{Conflict of interest}

The authors declare no conflict of interest.

\section{References}

1. Wang M, Munch IC, Hasler PW, Prünte C, Larsen M. Central serous chorioretinopathy. Acta Ophthalmol (Copenh) 2008; 86: 126-45.

2. Das UN. Diabetic macular edema, retinopathy and agerelated macular degeneration as inflammatory conditions. Arch Med Sci 2016; 12: 1142-57.

3. Kitzmann A, Pulido J, Diehl N, Hodge D, Burke J. The incidence of central serous chorioretinopathy in Olmsted County, Minnesota, 1980-2002. Ophthalmology 2008; 115: 169-73.

4. Spaide RF, Campeas L, Haas A, et al. Central serous chorioretinopathy in younger and older adults. Ophthalmology 1996; 103: 2070-9; discussion 2079-80.

5. How ACSW, Koh AHC. Angiographic characteristics of acute central serous chorioretinopathy in an Asian population. Ann Acad Med Singapore 2006; 35: 77-9.

6. Desai UR, Alhalel AA, Campen TJ, Schiffman RM, Edwards PA, Jacobsen GR. Central serous chorioretinopathy in African Americans. J Natl Med Assoc 2003; 95 : 553-9. 
7. Nowak M, Smigielski J, Jurowski P. The prevalence and pattern of retinal diseases in a sample population of older adults in the city of Lodz, Poland. Klin Oczna 2017; 119: $145-8$.

8. Tittl MK, Spaide RF, Wong D, et al. Systemic findings associated with central serous chorioretinopathy. Am J Ophthalmol 1999; 128: 63-8.

9. Daruich A, Matet A, Dirani A, et al. Central serous chorioretinopathy: recent findings and new physiopathology hypothesis. Prog Retin Eye Res 2015; 48: 82-118.

10. Bennett G. Central serous retinopathy. $\mathrm{Br} J$ Ophthalmol 1955; 39: 605-18.

11. Rasquin F. Central serous corticoid and chorioretinopathy. Bull Soc Belge Ophtalmol 2007; 304: 83-8.

12. Ersoz MG, Arf S, Hocaoglu M, Sayman Muslubas I, Karacorlu $M$. Patient characteristics and risk factors for central serous chorioretinopathy: an analysis of 811 patients. Br J Ophthalmol 2019; 103: 725-9.

13. Pociej-Marciak W, Karska-Basta I, Ozog-Baran J, KubickaTrzaska A, Filemonowicz-Skoczek A, RomanowskaDixon B. The use of mineralocorticoid receptor antagonists in chronic central serous chorioretinopathy. Klin Oczna 2016; 118: 48-54.

14. Tsai DC, Chen SJ, Huang CC, et al. Epidemiology of idiopathic central serous chorioretinopathy in Taiwan, 2001-2006: a population-based study. PLoS One 2013; 8: e66858.

15. Breukink MB, Dingemans AJ, den Hollander Al, et al. Chronic central serous chorioretinopathy: long-term follow-up and vision-related quality of life. Clin Ophthalmol Auckl NZ 2017; 11: 39-46.

16. Zhou M, Bakri SJ, Pershing S. Risk factors for incident central serous retinopathy: case-control analysis of a US national managed care population. $\mathrm{Br} J$ Ophthalmol 2019; 103: 1784-8.

17. Liew G, Quin G, Gillies M, Fraser-Bell S. Central serous chorioretinopathy: a review of epidemiology and pathophysiology. Clin Experiment Ophthalmol 2013; 41: 201-14.

18. Shulman S, Goldenberg D, Schwartz R, et al. Oral rifampin treatment for longstanding chronic central serous chorioretinopathy. Graefes Arch Clin Exp Ophthalmol Albrecht Von Graefes. Arch Klin Exp Ophthalmol 2016; 254: 15-22.

19. Loo RH, Scott IU, Flynn HW, et al. Factors associated with reduced visual acuity during long-term follow-up of patients with idiopathic central serous chorioretinopathy. Retina 2002; 22: 19-24.

20. Depta A, Jewczak M, Skura-Madziała A. Quality of life of patients from rural and urban areas in Poland with head and neck cancer treated with radiotherapy. A study of the influence of selected socio-demographic factors. Arch Med Sci 2017; 13: 1474-82.

21. Palomo-López P, Calvo-Lobo C, Becerro-de-Bengoa-Vallejo $R$, et al. Quality of life related to foot health status in women with fibromyalgia: a case-control study. Arch Med Sci 2019; 15: 694-9.

22. Teng Y, Wang S, Wang N, Muhuyati. STOP-Bang questionnaire screening for obstructive sleep apnea among Chinese patients with type 2 diabetes mellitus. Arch Med Sci 2018; 14: 971-8.

23. The World Health Organization Quality of Life assessment (WHOQOL): position paper from the World Health Organization. Soc Sci Med 1995; 41: 1403-9.

24. Sułkowski L, Matyja M, Pasternak A, Matyja A. WHOQOL-BREF survey of quality of life among dialyzed endstage renal disease patients. Arch Med Sci Civil Dis 2018; 3: e112-120.
25. Türkcü FM, Şahin A, Bez Y, et al. Vision-related quality of life in patients with chronic central serous chorioretinopathy. Semin Ophthalmol 2015; 30: 272-5.

26. Sahin A, Bez Y, Kaya MC, Türkcü FM, Sahin M, Yüksel H. Psychological distress and poor quality of life in patients with central serous chorioretinopathy. Semin Ophthalmol 2014; 29: 73-6.

27. Lajmi H, Hmaied W, Ben Jalel W, Akremi A, El Fekih L. Central serous chorioretinopathy: professional repercussions among agents of the internal security forces. J Fr Ophtalmol 2018; 41: 739-43.

28. European Glaucoma Society. Terminology and guidelines for glaucoma. $4^{\text {th }}$ ed. 2014

29. Nickels S, Schuster AK, Singer S, et al. The National Eye Institute 25-Item Visual Function Questionnaire (NEI VFQ-25) - reference data from the German population-based Gutenberg Health Study (GHS). Health Qual Life Outcomes 2017; 15: 156.

30. Brola W, Opara J, Fudala M, Czernicki J, Szwejkowski W. Polska adaptacja i analiza walidacyjna Kwestionariusza Funkcji Wzrokowych (Visual Function Questionnaire VFQ-25) u chorych ze stwardnieniem rozsianym. Wiad Lek 2010; LXIII: 161-70.

31. Mangione CM, Lee PP, Gutierrez PR, et al. Development of the 25-item National Eye Institute Visual Function Questionnaire. Arch Ophthalmol 2001; 119: 1050-8.

32. Broman AT, Munoz B, West SK, et al. Psychometric properties of the 25-item NEI-VFQ in a Hispanic population: Proyecto VER. Invest Ophthalmol Vis Sci 2001; 42: 606-13.

33. Lehmann M, Bousquet $E$, Beydoun T, Behar-Cohen $F$. PACHYCHOROID: an inherited condition? Retina 2015; 35: 10-6.

34. Dong LM, Childs AL, Mangione CM, et al. Health- and vision-related quality of life among patients with choroidal neovascularization secondary to age-related macular degeneration at enrollment in randomized trials of submacular surgery: SST report no. 4. Am J Ophthalmol 2004; 138: 91-108.

35. Bączyk G, Kozłowska K. The role of demographic and clinical variables in assessing the quality of life of outpatients with rheumatoid arthritis. Arch Med Sci 2018; 14: 1070-9.

36. Mirczak A, Tobiasz-Adamczyk B, Brzyski P, Kulig J, Nowak W. Porównanie jakości życia pacjentów w wieku co najmniej 65 lat oraz grupy chorych poniżej 64. roku życia po operacyjnym leczeniu raka jelita grubego. Gerontol Pol 2012; 20: 28-37.

37. Żmijewska-Tomczak M, Milecki P, Olek-Hrab K, et al. Factors influencing quality of life in patients during radiotherapy for head and neck cancer. Arch Med Sci 2014; 10: $1153-9$ 